\title{
Input-Occupancy-Output Analysis of Industrial Wastewater Discharge Coefficients and Backward and Forward Linkages: Multi-Regional Occupancy*
}

\author{
TANG Zhipeng $\cdot$ XIA Yan
}

DOI: $10.1007 / \mathrm{s} 11424-015-3120-6$

Received: 15 May 2013 / Revised: 11 September 2014

(C)The Editorial Office of JSSC \& Springer-Verlag Berlin Heidelberg 2015

\begin{abstract}
This paper provides an extended input-occupancy-output analysis of wastewater discharge coefficients, as well as backward and forward linkages of Chinese multi-regional industrial sectors in 2007. The results show that the direct and total industrial wastewater discharge coefficients of most of the provincial industrial sectors in China's Eastern region are lower than those of the whole country. Both backward and forward linkages of fixed-asset occupancy in industrial sectors in China's Central and Western regions are strong. The dissimilarity of cross-sectional data of the relevant industrial wastewater discharge coefficients and linkages in multi-regional input-output analysis becomes bigger as regions are divided more extensively.
\end{abstract}

Key words Backward linkage, forward linkage, industrial wastewater discharge, input-occupancyoutput analysis.

\section{Introduction}

As an integral part of water resources management, wastewater discharge has attracted worldwide attention. This attention is largely due to the scarcity of freshwater resources and heightened environmental concerns ${ }^{[1-3]}$. Meanwhile, economic considerations are also becoming increasingly important amid the introduction of market-based mechanisms in water resources management. Discharged wastewater from municipalities and industries has been an additional

\footnotetext{
TANG Zhipeng

Key Laboratory of Regional Sustainable Development Modeling, Institute of Geography Sciences and Natural Resources Research, Chinese Academy of Sciences, Beijing 100101, China.

XIA Yan (Corresponding author)

Center for Energy and Environmental Policy Research, Institute of Policy and Management, Chinese Academy of Sciences, Beijing 100190, China. Email: xiayan@casipm.ac.cn.

*This was supported by the National Natural Science Foundation of China under Grant Nos. 41201129 and 71203213, and the Science and Technology Service Network Initiative of the Chinese Academy of Sciences under Grant No. KFJ-EW-STS-003.

$\diamond$ This paper was recommended for publication by Editor YANG Cuihong.

Springer
} 
environmental burden to the water supply in many parts of the world, especially in areas where water resources are scarce but population and economic growth is rapid ${ }^{[4]}$. The situation in China is a typical case in point. Today, total Chinese wastewater discharges are increasing considerably with China's economic development. From 2000 to 2012, the wastewater discharge increased from 41.5 billion tons to 68.4 billion tons. Industrial wastewater and domestic sewage are the main two emitting sources. Though industrial wastewater had less discharge than domestic sewage from 2000 to 2012, domestic sewage has a large number of organic compounds which generally do not contain poison, while industrial wastewater has complex constituents and often contains heavy metals such as arsenic and cadmium that are difficult to degrade. Soil that has been contaminated by the heavy metals in industrial wastewater discharge is very difficult to remediate solely by cutting off the pollution source because this type of contamination is not completely reversible. Because industrial wastewater has many characteristics, such as a wide, complex variety of constituents, high chemical oxygen demand and toxins, the environment may be very seriously polluted and destroyed in the absence of effective pollutant reduction measures ${ }^{[5,6]}$. In the 20th century, the Minamata disease event and the Itai-itai disease event in Japan were two of the eight public environmental events in the world that were caused by pollution from industrial wastewater discharges. The majority of studies thus far have focused on the technical treatment ${ }^{[7,8]}$ and the forecasting ${ }^{[9-11]}$ of industrial wastewater discharge. A statement on the Chinese Ministry of Environmental Protection website declares that the authorities of 30 provinces, autonomous regions and municipalities are required to complete 242 projects on industrial wastewater discharge reduction in $2014^{[12]}$. Therefore, seen from both environmental sustainability protection and public health standpoints, it makes sense to devote more attention to industrial wastewater discharge than domestic sewage discharge. From 1991 to 2007, Chinese industrial wastewater discharge was not closely related to total industrial output growth, as shown in Figure 1.

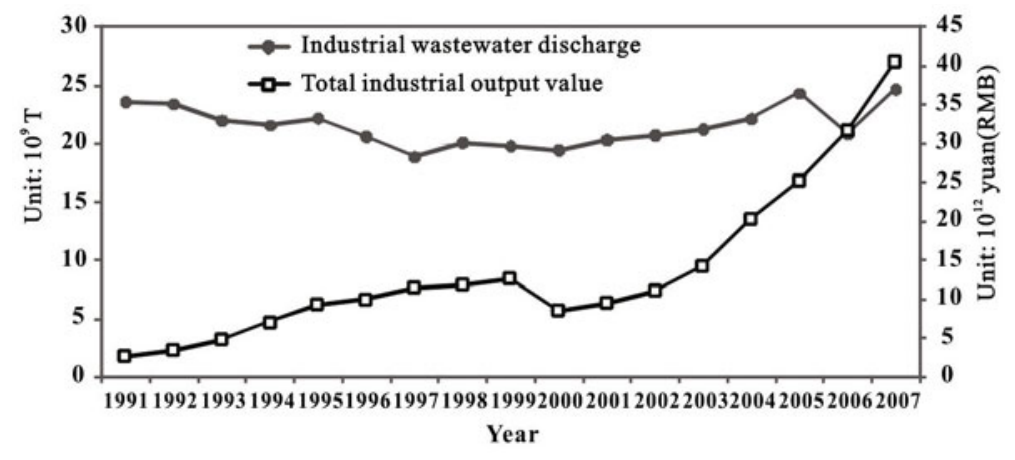

Figure 1 Gross amount of industrial wastewater discharge and total industrial output value in China from 1991 to 2007 (Tang, et al. ${ }^{[13]}$ )

The above graph demonstrates that, by and large, the total industrial output value in China increased significantly from 1991 to 2007, while the gross amount of industrial wastewater discharge did not rise during the same period. This is an interesting phenomenon, and indicates 
that the direct discharge amount of one output unit declined in China from 1991 to 2007. According to Chinese spatial distribution statistics, Jiangsu, Guangdong and Zhejiang were the top three discharging provinces of Chinese industrial wastewater in 2007. The discharge proportions for these three provinces in China are $10.9 \%, 10.0 \%$ and $8.2 \%$, respectively. In the last decade, the environment has become an increasingly prominent global issue whose significance is perhaps trumped only by its complexity. The study of the environmental pollution issue is generally understood as the study of an economic structure. Time and again, insight into which emissions pollute the environment and their impacts has been proven to be of prime importance to economic analysis and policy. Pollution is a by-product of regular economic activities. For example, the discharge of polluted water into streams and lakes is directly linked to the level of output of steel, paper, textile and other water-using industries ${ }^{[14]}$. The factors affecting industrial wastewater discharge primarily include the economic scale, economic structure and level of development of treatment technologies ${ }^{[13,15]}$. Due to the uneven economic development that China has experienced, the economic scale, economic structure and level of development of treatment technologies are different in each province in China ${ }^{[16,17]}$. At the same time, as mentioned previously, industrial wastewater that is a by-product of industrial products does little to reduce the total discharges during Chinese economic growth. The regional economic differences in the above-mentioned aspects are often ignored if we only compare provincial industrial wastewater discharge amounts. Thus, comparing different provincial industrial wastewater discharges per unit of economic output is a reasonable approach in terms of synthesizing economic and environmental benefits; therefore, taking the discharge coefficient as an evaluation index is an inevitable consequence. Some important discharge coefficients contribute to recognizing the key sectors that influence industrial wastewater discharge ${ }^{[18]}$.

From an environmental economics perspective, research methods primarily include inputoutput analysis, regression analysis, and so on. The advantage of Input-Output (IO) analysis is that it can easily reflect the complicated linkages in national economic structure, including explicit direct linkages and implicit indirect linkages. Input-output analysis can describe and explain the level of each sector in a given national economy in terms of its relationships to corresponding levels of activity in all of the other sectors, and even the spatial patterns of the economy may be described and explained by a complex multi-regional input-output approach ${ }^{[13]}$. With the development of globalization, multi-regional economic activities are becoming more frequent, and polluting events are more likely to occur in multiple regions. Input-output tables reflect the interdependence between factor inputs and outputs in production.

We have noted that to ensure smooth production, the production process inevitably needs to take into account other resources, such as the land, water resources, mineral resources, human capital, and available workshops and equipment. These resources have two characteristics. Firstly, they are different from raw materials, such as timber, electricity, fertilizer, and so on, in that they will not be regarded as being consumed in the production process. However, these resources are slowly consumed during production, meaning that the current input will not be completely consumed immediately and will be depreciated and lost gradually in the span of a few years. Secondly, the traditional input-output model, which was defined in an 
input-occupancy-output model set up by Chen in the $1980 \mathrm{~s}^{[19]}$, ignored occupancies of stocks, such as the occupancy of the land and factory buildings. All of the elements in the inputoutput table deal with economic flow, but economic stocks (such as fixed assets and lands) are often ignored despite their importance in economic development. Because the normal inputoutput model did not include an economic stock section, Chen, et al. ${ }^{[20,21]}$ introduced the occupancy of economic stock and proposed the Input-Occupancy-Output (IOO) table and the Input-Occupancy-Output (IOO) model.

There are only economic flow coefficients of all of the sectors in the complicated linkages of traditional IO analysis, while economic stock coefficients are also introduced in all of the sectors in the complicated linkages of IOO analysis. Certainly, the IO model is an appropriate mathematical tool for addressing the problem of industrial structure, especially when associated with environmental protection $^{[13,22]}$. For Chinese environmental protection problems, characteristics such as the imports intermediate input, the occupancy and the regional disparity need to be reflected in the IO analysis. The occupancy is the foundation of input in modern production. The occupancy includes stocks such as labor force and fixed assets, and the input includes flow such as investment and export ${ }^{[23]}$. To improve production levels, more experienced labor forces and advanced equipment must be applied, meaning that the occupied materials are inflows for production. The occupancy in the IO model is usually applied to a signal region (such as the national scale), but the question remains at to how it is applied at the multi-region scale. Therefore, this paper proposes an extended, multi-regional IOO model to reflect the occupancy characteristics of Chinese environmental problems on a multi-region scale.

This paper aims to propose an extended, multi-regional IOO model to reflect these characteristics of Chinese environmental problems. In this model, we assume that regional imports are non-competitive and that regional exports are integrated, that is, different export types are not differentiated. The remainder of this paper is structured as follows: Relevant literature is reviewed in Section 2. An extended multi-regional IOO model including fixed assets occupancies for each sector of the economy and the main data of empirical analysis is proposed in Section 3. The direct and total discharge coefficients of industrial wastewater, as well as the backward and forward linkages of industrial sectors' fixed-asset occupancies, are detailed in Section 4, and in Section 5 , we summarize this paper's purpose and present our conclusions.

\section{Literature Review}

Although many studies have been carried out on wastewater issues, including hydrological and physical studies, studies regarding economic factors as the demand-side driving forces of water problems are few and far between ${ }^{[24-26]}$. In addition, the majority of the previous studies have focused on the application of IO analyses to treatment of wastewater. IO analysis was set up by Leontief in the 1930s. This analysis extended the interregional IO model and the multiregional IO model in the $1950 \mathrm{~s}^{[27,28]}$. Because the traditional IO model ignored the occupancies of stocks (such as the occupancy of the land and factory buildings), an IOO model was set up by Chen in the $1980 \mathrm{~s}^{[19]}$. One of the earliest studies that considered wastewater treatment 
was performed by Victor ${ }^{[29]}$, whose work evaluates the impact of Canadian economic activity using an IO analysis. With respect to water-related environmental issues, research conducted by Harris and Rea ${ }^{[30]}$ was based on the use of IO tables to estimate the value of water resources in the U.S. Duchin developed the framework of the Environmental Input-Output (EIO) model based on Leontief's EIO model ${ }^{[31]}$. Duarte, et al. ${ }^{[32]}$ evaluated the internal effect and the induced effect of water consumption with an IO analysis in Spain. Velazquez proposed an IO model of water consumption and applied it to estimate Spain's consumption ${ }^{[33]}$. Lin proposed a hybrid IO model designed to analyze both the generation and treatment of wastewater in the metropolis of Tokyo ${ }^{[34]}$.

For Chinese environmental protection issues, characteristics such as the imported intermediate input, the occupancy and the regional disparity have to be reflected in an IO analysis.Ni et al. studied the local available treatment capacity and investment costs using a multi-objective analysis model based on an IO table in China ${ }^{[35]}$. Hubacek and Sun ${ }^{[36]}$ extended the IO tables to forecast water consumption in China. Okadera, et al. ${ }^{[37]}$ estimated the demand for water and the water pollution generated in Chongqing using a regional IO table. Guan and Hubacek $^{[38]}$ considered the discharged wastewater based on the standard IO model. Two important papers on water IOO analysis were published by Chen, et al., focusing on different river basins in China ${ }^{[39,40]}$. In addition to the literature on IOO analysis, the methodological issues involved in IO technology, such as aggregation issues ${ }^{[1,42]}$, imports assumptions ${ }^{[43]}$, exports assumptions $^{[44,45]}$, and inter-regional feedback effects ${ }^{[46]}$, have been discussed in recent publications. Zhang, et al. ${ }^{[47]}$ published a recent water study using China's provincial data from 2002 and 2007.

Dietzenbacher, et al. ${ }^{[44]}$ was the first study to examine the impacts of separating processing exports from exports on China's embodied emissions. Su, et al. ${ }^{[45]}$ measured China's emissions embodied in its exports and analyzed the possible impacts of the results using a multi-regional IO model. By comparing the differences in results between different sectors, Su, et al. ${ }^{[41]}$ explored sector aggregation issues and concluded that different sector divisions could affect the accuracy of the results obtained in each sector. The advantages of using the multi-regional IO data are as follows: 1) To show the results at a detailed regional level and reduce the impacts of spatial aggregation ${ }^{[42]}$ and 2) to account for inter-regional feedback effects ${ }^{[46]}$. However, the aforementioned studies are all based on uniform production structure, which fails to consider the occupancy of fixed assets.

The current paper, which focuses on Chinese industrial wastewater discharge, is most relevant to two previous papers regarding utilization of China's water resources ${ }^{[40,47]}$, but there are some differences between them. Firstly, the paper by Chen, et al. ${ }^{[40]}$ used single regional IOO data, and the paper by Zhang, et al. ${ }^{[4]}$ used Chinese provincial IO data from 2002 and 2007, which are also single regional IO data. The division of China into nine river basins was based on natural water systems in the paper by Chen, et al. ${ }^{[40]}$, while the division of China into four major economic plates (Western, Eastern, Northwestern and Central China) in this paper is based on the administrative provinces proposed by the Development Research Center of the State Council. Therefore, this paper applies multi-regional IOO data.

算 Springer 
Secondly, the papers by Chen, et al. ${ }^{[40]}$ and Zhang, et al. ${ }^{[47]}$ focus on water input per unit of economic output from the perspective of natural resource utilization, while this paper focuses on industrial wastewater discharge of per unit of economic output from the perspective of environmental pollution emissions. In addition, the industrial sector obviously has more fixedasset occupations, such as machinery and buildings, than other sectors do. Presumably, the industrial sector has more polluting emissions than other sectors do, and the polluting emissions caused by the depreciation of these occupations cannot be ignored. Hence, taking industrial wastewater discharge as an example is representative in environmental IOO analysis.

\section{Data and Methodology}

\subsection{Data}

The data in this study were obtained primarily from an IO table of 30 sectors of 30 provinces, autonomous regions and municipalities in mainland China for the year 2007, which was compiled by researchers at the Institute of Geographic Sciences and Natural Resources Research of the Chinese Academy of Sciences and the National Statistics Bureau of China ${ }^{[48]}$. In this noncompetitive imports IO table we aggregate the 30 Chinese administrative areas into 4 regions, as follows: The Eastern region (including Beijing, Tianjin, Hebei, Shandong, Shanghai, Jiangsu, Zhejiang, Fujian, Guangdong and Hainan), the Central region (including Shanxi, Shaanxi, Henan, Inner Mongolia, Hubei, Hunan, Jiangxi and Anhui), the Western region (including Yunnan, Guizhou, Sichuan, Chongqing, Guangxi, Gansu, Qinghai, Ningxia and Xinjiang) and the Northeastern region (including Liaoning, Jilin and Heilongjiang). Furthermore, we aggregate these 30 administrative areas into one country. By doing so, we obtain three types of IOO data: Multi-regional IOO data for 30 administrative areas, multi-regional IOO data for 4 regions and single-regional IOO data for the entire country.

We pay more attention to spatial differences in these cross-sectional data. Due to lack of industrial wastewater discharge data from some provincial-specific industrial branch sectors, we aggregate the 30 sectors into 6 sectors in all three types of IOO data. These 6 sectors' numbers and names are depicted as follows: 1, agriculture; 2, industry; 3, construction; 4, transport and warehousing; 5, wholesale and retail trade; and 6 , other social services. The relevant data regarding Chinese provincial industrial wastewater discharge amounts and fixedasset investments are from China Statistic Yearbook 2008 ${ }^{[49]}$. We aggregated China's fixedasset investments in 2006 and 2007 based on China's fuel ethanol IOO table from 2005 ${ }^{[50]}$, and obtained China's 6-sector occupancy table in fixed-asset year 2007, in which the sectoral division is the same as that performed for the aforementioned three types of IOO data. We divided China's occupancy table of fixed assets in 2007 into the 30-provincial, 6-sector occupancy table according to the 6 -sector provincial structural proportion of fixed-asset investments in 2007, and then it was merged and compiled into the above three types of IOO data. 


\subsection{Methodology}

\subsubsection{Direct and Total Industrial Wastewater Discharge Coefficient}

To compare different regional industrial wastewater discharge levels, the first step was to derive the Direct Industrial Wastewater Discharge Coefficient (DIWDC) for single regions and multi-regions. The DIWDC can be expressed as Equations (1) and (2), respectively:

$$
\begin{aligned}
& E=\left[e_{j}\right], \quad e_{j}=w_{j} / x_{j}, \quad \text { single }- \text { region; } \\
& E^{q}=\left[e_{j}^{q}\right], \quad \mathrm{e}_{j}^{q}=w_{j}^{q} / x_{j}^{q}, \quad \text { multi - region; }
\end{aligned}
$$

where $E$ (or $E^{q}$ ) is the vector of DIWDCs (measured in ton $/ 10^{3}$ Yuan in this study), $e_{j}$ (or $e_{j}^{q}$ ) is the DIWDC of sector $j$ (of region $q$ ), calculated by dividing $w_{j}$ (or $w_{j}^{q}$ ), the direct industrial wastewater discharge amount of sector $j$ by $x_{j}\left(\right.$ or $x_{j}^{q}$ ), the total output of sector $j$ (in monetary terms). The IO analysis of the total Industrial Wastewater Discharge Coefficient (IO-TIWDC) $f_{j}$ (or $f_{j}^{q}$ ) of a single region (multi-region) indicates the total industrial wastewater discharge amount in sector $j$ (of region $q$ ) throughout the whole production chain, and single-region and multi-region IO-TIWDCs can be derived from Equations (3) and (4), respectively:

$$
\begin{aligned}
& F=\left[f_{j}\right], \quad f_{j}=e_{j}+e e_{j}=e_{j}+\sum_{i} f_{i} a_{i j}, \quad \text { single }- \text { region; } \\
& F^{q}=\left[f_{j}^{q}\right], \quad f_{j}^{q}=e_{j}^{q}+e e_{j}^{q}=e_{j}^{q}+\sum_{p} \sum_{i} f_{i}^{p} a_{i j}^{p q}, \quad \text { multi }- \text { region }
\end{aligned}
$$

$F\left(\right.$ or $F^{q}$ ) is the vector of IO-TIWDCs, $f_{j}$ (or $f_{j}^{q}$ ) is the IO-TIWDC of sector $j$ (of region $q$ ), which gives the amount of industrial wastewater discharge for the production of one unit of final demand of sector $j$ (of region $q$ ). This does not only include direct discharge $e_{j}$ (or $e_{j}^{q}$ ) but also includes indirect discharge $e e_{j}$ ( or $e e_{j}^{q}$ ). The element of direct input to the matrix is $a_{i j}$ (or $a_{i j}^{p q}$ ), which indicates the direct consumption amount of sector $i$ (of region $p$ ) required to meet one unit of total output of sector $j$ (of region $q$ ). Equations (3) and (4) reflect the interdependence between factor inputs and outputs in the production chain, resulting in total industrial wastewater discharge. However, the calculation of total industrial wastewater discharge does not include any section resulting from the depreciation of fixed assets. Chen proposed IOO analysis to correct this omission ${ }^{[20]}$. For single-region input-output analysis, the IOO-TIWDC can be expressed as Equation (5):

$$
\widetilde{F}=\left[\tilde{f}_{j}\right], \quad \tilde{f}_{j}=e_{j}+\sum_{i} \tilde{f}_{i} a_{i j}+\sum_{i} \tilde{f}_{i} r_{i} d_{i j}, \quad \text { single }- \text { region; }
$$

where $\widetilde{F}$ is the new vector of IOO-TIWDCs, is the IOO-TIWDC of sector $j$, which gives the amount of industrial wastewater discharge for the production of one unit of final demand of sector $j$ including the depreciation of fixed-asset occupancy of sector $j$, and $r_{i}$ is the depreciation rate of sector $i$. The variable $d_{i j}$ represents the direct fixed-asset occupation amount of sector $i$ to meet one unit of total output in sector $j$. When Equations (3) and (5) are compared, is obviously greater than $f_{j}$ due to the introduction of an additional discharge with the depreciation of fixed-asset occupancy. IOO analysis is usually applied for single regions, such as at the 
national scale. Similar to the above Equations, multi-regional IOO-TIWDC can be expressed as Equation (6):

$$
\widetilde{F}^{q}=\left[\widetilde{f}_{j}^{q}\right], \quad \widetilde{f}_{j}^{q}=e_{j}^{q}+\sum_{p} \sum_{i} \widetilde{f}_{i}^{p} a_{i j}^{p q}+\sum_{p} \sum_{i} \widetilde{f}_{i}^{p} r_{i}^{p} d_{i j}^{p q}, \quad \text { multi }- \text { region; }
$$

Equation (6) indicates multi-regional IOO-TIWDC, including implicit discharge with the depreciation of fixed-asset occupancy among multiple regions ${ }^{[51]}$. From the above Equations (1)-(6), it is clear that DIWDCs turn into IOO-TIWDCs through all sorts of linkages in $a_{i j}$ (or $a_{i j}^{p q}$ ) and $d_{i j}$ (or $d_{i j}^{p q}$ ). In input-output analysis, there are important linkages, including the backward linkage and the forward linkage, based on the Leontief inverse coefficients ${ }^{[52]}$. In later literature, some scholars differentiated the backward linkage from the forward linkage. They proposed that the forward linkage should be based on Ghosh inverse coefficients ${ }^{[23]}$. The depreciation of fixed-asset occupancy is important for the IOO-TIWDC, and therefore it must be included in the industrial linkage expressed as Equations (5) and (6).

\subsubsection{Backward Linkage and Forward Linkage of Fixed-asset Occupancy}

For $\mathrm{n}$ sectors in a single region, the backward linkage and the forward linkage of fixed-asset occupancy can be expressed as Equation (7) ${ }^{[23]}$ :

$$
B L_{j}=\frac{\sum_{i=1}^{n} \sum_{s=1}^{n} d_{i s} u_{s j}}{\frac{1}{n} \sum_{i=1}^{n} \sum_{s=1}^{n} \sum_{j=1}^{n} d_{i s} u_{s j}} ; F L_{i}=\frac{\sum_{s=1}^{n} \sum_{j=1}^{n} v_{i j} d_{j s}}{\frac{1}{n} \sum_{i=1}^{n} \sum_{s=1}^{n} \sum_{j=1}^{n} v_{i j} d_{j s}}, \quad \text { single - region; }
$$

$B L_{j}$ is called the backward linkage coefficient of fixed-assets in the sector ' $j$ ', that is to say, the extent of all the sectors' fixed-asset demands caused by an additional unit of final product in the sector ' $j$ '. $u_{i j}$ is the Leontief inverse matrix coefficient, and $F L_{i}$ is called the forward linkage coefficient of fixed assets in the sector ' $i$ ', that is to say, the extent of all the sectors' fixed-asset supply caused by an additional unit of primary input in the sector ' $i$ '. $v_{i j}$ is the Ghosh inverse matrix coefficient. A value of $B L_{j}>1$ indicates that a unit change in final demand in sector $j$ would create an above-average increase in activity in the economy; similarly, if $F L_{i}>1$, it indicates that a unit change in all sectors' primary input would create an above-average increase in sector $i$. When multiple regions are considered, supposing that there are $m$ regions and each region has $n$ sectors, the backward linkage and the forward linkage of fixed-asset occupancy are classified for single-regions and inter-regions. They are expressed as follows:

$$
\begin{aligned}
& B L_{j}^{z}=\frac{\sum_{t=1}^{m} \sum_{k=1}^{m} \sum_{i=1}^{n} \sum_{s=1}^{n} d_{i s}^{t k} u_{s j}^{k z}}{\frac{1}{m \times n} \sum_{z=1}^{m} \sum_{j=1}^{n} \sum_{t=1}^{m} \sum_{k=1}^{m} \sum_{i=1}^{n} \sum_{s=1}^{n} d_{i s}^{t k} u_{s j}^{k z}} ; \\
& F L_{i}^{t}=\frac{\sum_{k=1}^{m} \sum_{z=1}^{m} \sum_{s=1}^{n} \sum_{j=1}^{n} v_{i j}^{t k} d_{j s}^{k z}}{\frac{1}{m \times n} \sum_{z=1}^{m} \sum_{i=1}^{n} \sum_{k=1}^{m} \sum_{t=1}^{m} \sum_{s=1}^{n} \sum_{j=1}^{n} v_{i j}^{t k} d_{j s}^{k z}}, \quad \text { single - region; }
\end{aligned}
$$


and

$$
\begin{aligned}
B L_{j}^{t z(t \neq z)} & =\frac{\sum_{k=1}^{m} \sum_{i=1}^{n} \sum_{s=1}^{n} d_{i s}^{t k} u_{s j}^{k z}}{\frac{1}{n} \sum_{j=1}^{n} \sum_{k=1}^{m} \sum_{i=1}^{n} \sum_{s=1}^{n} d_{i s}^{t k} u_{s j}^{k z}} ; \\
F L_{i}^{t z(t \neq z)} & =\frac{\sum_{k=1}^{m} \sum_{s=1}^{n} \sum_{j=1}^{n} v_{i j}^{t k} d_{j s}^{k z}}{\frac{1}{n} \sum_{i=1}^{n} \sum_{k=1}^{m} \sum_{s=1}^{n} \sum_{j=1}^{n} v_{i j}^{t k} d_{j s}^{k z}}, \quad \text { inter - region; }
\end{aligned}
$$

Here $B L_{j}^{z}$ represents the extent of all the sectors' fixed-asset demands in all of the regions caused by an additional unit of final product in the sector ' $j$ ' in region ' $z$ ', called the backward linkage coefficient of fixed assets in the sector ' $j$ ' in region ' $z$ '. In addition, $F L_{i}^{t}$ means the extent of all the sectors' fixed-asset supplies in all of the regions caused by an additional unit of primary input product in the sector ' $i$ ' in region ' $t$ ', called the forward linkage coefficient of fixed assets of the sector ' $i$ ' in region ' $t$ '. If $B L_{j}^{z}>1$, the backward linkage of fixed assets in sector ' $j$ ' in region ' $z$ ' is strong, otherwise it is weak. In addition, if $F L_{i}^{t}>1$, the forward linkage of fixed assets in sector ' $i$ ' in region ' $t$ ' is strong, otherwise it is weak. $B L_{j}^{t z}$ represents the extent of all the sectors' fixed-asset demands in region ' $t$ ' caused by an additional unit of final product in the sector ' $j$ ' in region ' $z$ ', called the backward linkage coefficient of fixed assets between region ' $t$ ' and region ' $z$ '. The variable $F L_{i}^{t z}$ indicates the extent of all the sectors' fixed-asset supplies in region ' $z$ ' caused by an additional unit of primary input product in the sector ' $i$ ' in region ' $t$ ', called the forward linkage coefficient of fixed assets between region ' $z$ ' and region ' $t$ '. If $B L_{j}^{t z}>1$, the backward linkage of fixed assets in region ' $t$ ' resulting from sector ' $j$ ' of region ' $z$ ' is strong, otherwise it is weak. If $F L_{i}^{t z}>1$, the forward linkage of sector ' $i$ ' in region ' $t$ ' resulting in fixed assets in region ' $z$ ' is strong, otherwise it is weak.

\subsubsection{The Dissimilarity of Coefficients and Linkages}

The dissimilarity of the same type of coefficients and linkages for the different regional classification levels presents the regional differences. There are more similarities for these regions if they have fewer regional differences. Uniform policy-making or divergent policy-making in many regions must be based on whether there are large regional differences. The coefficient of variation and the Gini coefficient are used to measure the dissimilarity between different regions. They are expressed as follows, respectively:

$$
C=\frac{S}{V}
$$

where $C$ is the coefficient of variation, $S$ is the standard deviation of samples, and $V$ is the mean of the samples. If $C$ is large, the dissimilarity is also large. Likewise, if $C$ is small, the dissimilarity is small. The latter can be written as:

$$
G=\frac{\sum_{i=1}^{n} \sum_{j=1}^{n}\left|y_{j}-y_{i}\right|}{2 n \sum_{i=1}^{n} y_{i}},
$$

where $G$ is the Gini coefficient, $y_{i}$ is the observation of samples, and $n$ is number of samples. If $G$ is large, the dissimilarity is also large, and the opposite is also true.

典 Springer 


\section{Results}

\subsection{Wastewater Discharge Coefficients of Chinese Multi-regional Industrial Sec- tors}

The three types of IOO data show (Figure 2) that the DIWDC of the industrial sector of China was 0.51 ton $/ 10^{3}$ Yuan in 2007. The DIWDCs of the industrial sector in the Eastern region, Central region, Western region and Northeastern region were 0.39, 0.65, 1.14 and 0.49 ton $/ 10^{3}$ Yuan in 2007 , respectively. The DIWDCs of the industrial sectors in both the Central region and Western region were higher than that of the whole country, while the situation for the Eastern region and Northeastern region was just the opposite. In the Eastern region, the DIWDCs in the industrial sectors of Fujian (0.91 ton $/ 10^{3}$ Yuan) and Hainan (0.52 ton $/ 10^{3}$ Yuan) were higher than that of the whole country; in the Central region, the DIWDCs of the industrial sectors of Shaanxi (0.71 ton/10 3 Yuan), Hubei (0.80 ton $/ 10^{3}$ Yuan), Hunan (0.96 ton $/ 10^{3}$ Yuan), Jiangxi ( 0.89 ton $/ 10^{3}$ Yuan) and Anhui ( 0.75 ton $/ 10^{3}$ Yuan) were higher than that of the whole country; in the Western region, the DIWDCs of the industrial sectors of Yunnan (0.73 ton $/ 10^{3}$ Yuan), Sichuan (0.94 ton $/ 10^{3}$ Yuan), Chongqing (1.12 ton/10 3 Yuan), Guangxi (2.71 ton $/ 10^{3}$ Yuan), Qinghai ( 0.77 ton $/ 10^{3}$ Yuan), Ningxia (1.66 ton $/ 10^{3}$ Yuan) and Xinjiang ( 0.56 ton $/ 10^{3}$ Yuan) were higher than that of the whole country; and in the Northeastern region, the DIWDCs of the industrial sectors of Jilin ( 0.56 ton/10 3 Yuan) were higher than that of the whole country.

Because of no industrial linkage and spatial association involved, the DIWDCs of the industrial sectors of Chinese provinces only depended on two variables, the direct industrial wastewater discharge amount and the total output of the sector. Though the total discharge amount in the Eastern region was much more than that of any of the other three regions, it was the total industrial output value that was much greater than in any of the other three regions. This means that the discharge amount per unit of gross industrial output value is lower for the Eastern region. To be specific, the proportion of industrial wastewater discharge in the Eastern region amounts to $49.8 \%$ of the value for whole country, which is 2.1 times that of the Central region, 2.6 times that of the Western region and 7.1 times that of the Northeastern region. By contrast, the proportion of the total output of the industrial sector in the Eastern region amounts to $65.4 \%$ of the value for the whole country, which is 3.5 times that of the Central region, 7.5 times that of the Western region and 9.1 times that of the Northeastern region. The provinces with high DIWDCs should focus on upgrading production technology to reduce direct industrial wastewater discharge.

When industrial linkages and spatial associations for the total discharge amount of a single region is considered, the indirect discharge amounts resulting from other sectors and other regions should be considered as well. Thus, it is necessary to calculate TIWDCs using IO analysis or IOO analysis. 


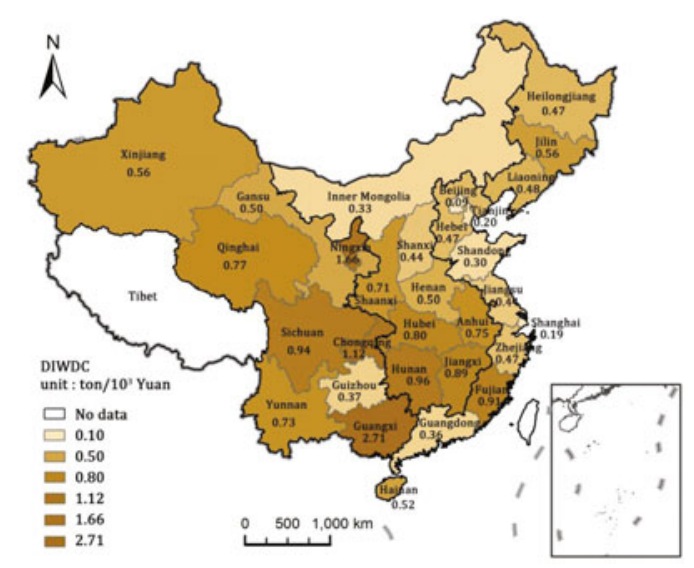

Figure 2 The DIWDCs of the industrial sectors of Chinese provinces (Unit: ton $/ 10^{3}$ Yuan)

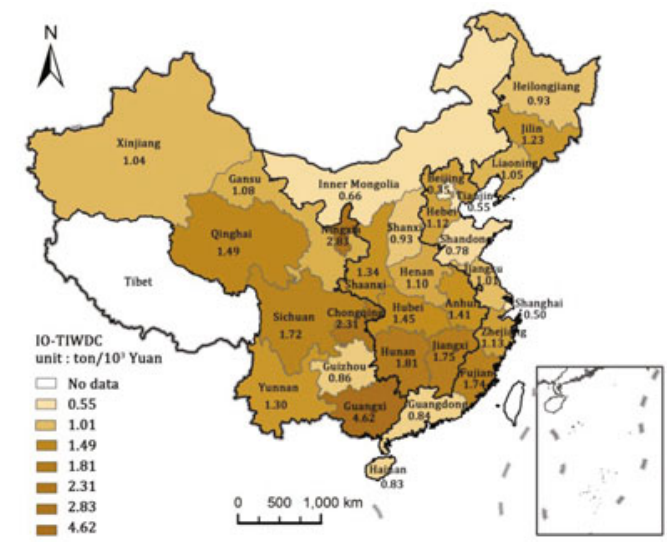

Figure 3 The IO-TIWDCs of the industrial sectors of Chinese provinces (Unit: ton $/ 10^{3}$ Yuan)

When traditional IO analysis was used (Figure 3), the IO-TIWDCs of the industrial sector in the Central region (1.29 ton $/ 10^{3}$ Yuan) and the Western region (2.07 ton $/ 10^{3}$ Yuan) were also both higher than that of the whole country (1.08 ton $/ 10^{3}$ Yuan). Furthermore, Hunan (1.81 ton $/ 10^{3}$ Yuan), Jiangxi (1.75 ton $/ 10^{3}$ Yuan) and Hubei (1.45 ton $/ 10^{3}$ Yuan) were the top three provincial regions with respect to IO-TIWDCs in the industrial sector of the Central region,

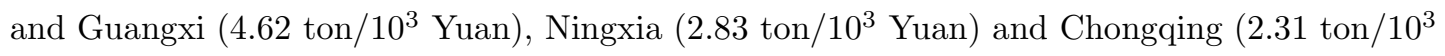
Yuan) were the top three provincial regions with respect to IO-TIWDCs in the industrial sector of the Western region. The orders of the IO-TIWDCs for the top three provincial regions were identical to that of the DIWDCs in both the Central region and Western region. As for the Eastern region, Beijing ( 0.35 ton $/ 10^{3}$ Yuan) was ranked as the lowest, and Heilongjiang (1.15 ton $/ 10^{3}$ Yuan) was ranked as the lowest in the Northeastern region.

As for the IOO analysis of the TIWDC with fixed-asset occupancy, the IOO-TIWDCs were higher than the IO-TIWDCs for the industrial sectors in all of the provinces (Figure 4). In the 
four regions of China, only the IOO-TIWDC of industrial sector in the Eastern region (1.00 ton $/ 10^{3}$ Yuan) was lower than that of the whole country (1.20 ton $/ 10^{3}$ Yuan). The empirical results reveal that, if the IO-TIWDC in one regional industrial sector is higher than that of the whole country, the same is also true for its IOO-TIWDC.

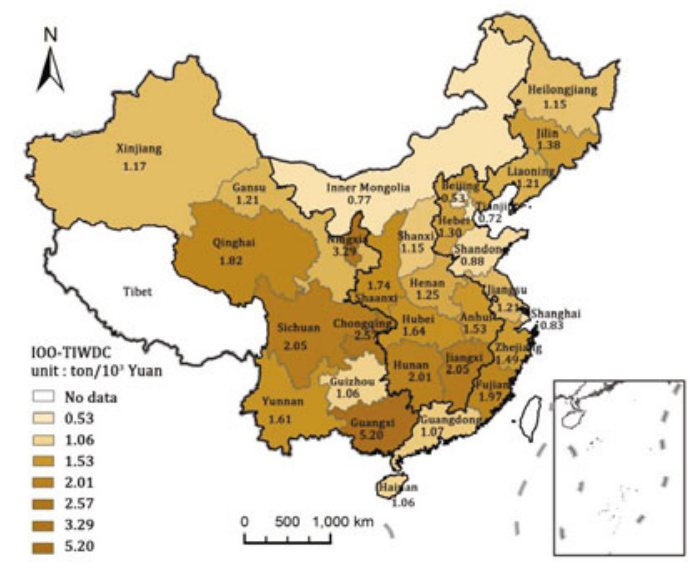

Figure 4 The IOO-TIWDCs of the industrial sectors of Chinese provinces (Unit: ton $/ 10^{3}$ Yuan)

Similar to the provincial IO-TIWDC in the Eastern region, which exceeded that of the whole country, IOO-TIWDCs in Fujian (1.86 ton/10 $0^{3}$ Yuan), Zhejiang (1.26 ton/10 3 Yuan) and Hebei (1.23 ton $/ 10^{3}$ Yuan) industrial sectors were all higher than that of the whole country. In the Central region, only IOO-TIWDCs in the Inner Mongolia (0.77 ton $/ 10^{3}$ Yuan), Shanxi (1.06 ton $/ 10^{3}$ Yuan) and Henan (1.19 ton $/ 10^{3}$ Yuan) industrial sectors were lower than that of the whole country. In addition, only the Guizhou ( 0.98 ton $/ 10^{3}$ Yuan) and Xinjiang (1.19 ton $/ 10^{3}$ Yuan) industrial sectors in the Western region had IOO-TIWDCs that were lower than that of the whole country, as with Heilongjiang (1.11 ton $/ 10^{3}$ Yuan) in the Northeastern region.

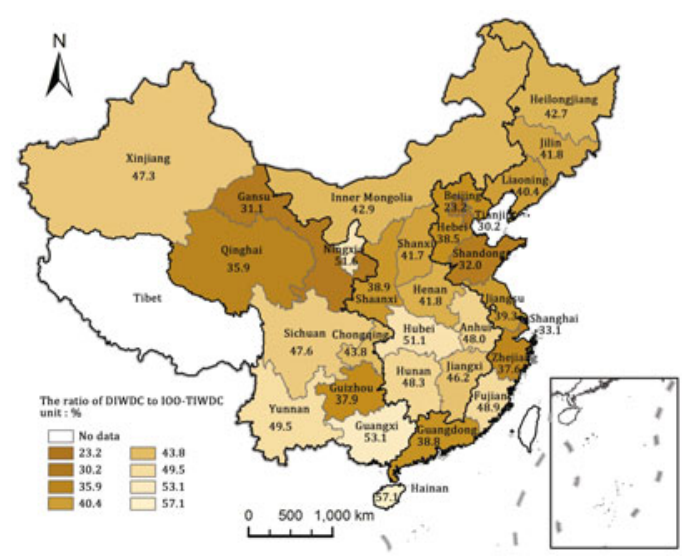

Figure 5 The ratio of DIWDC to IOO-TIWDCs in industrial sectors of Chinese provinces (Unit: \%) 
When regional DIWDCs and their respective IOO-TIWDCs were compared in the four Chinese regions, the ratio of DIWDC to IOO-TIWDC in the Eastern region is the lowest $(38.6 \%)$, followed by the Northeastern region (40.6\%), Central region (44.8\%), and Western region $(47.5 \%)$. Obviously, this type of ratio is much lower, meaning that this regional industrial sector had a much closer linkage with other sectors and other regions, resulting in higher amounts of indirect industrial wastewater discharge. In the Eastern region (Figure 5), Beijing (23.2\%), Shanghai (33.1\%), Tianjin (30.2\%), Shandong (32.0\%), Zhejiang (37.6\%) and Hebei $(38.5 \%)$ had lower ratios than that of the Eastern region, meaning that these provincial industrial linkages and spatial associations were stronger. Hainan had a higher DIWDC but a lower IOO-TIWDC, indicating that Hainan had weaker industrial linkages and spatial associations than the other provinces, while Beijing had stronger industrial linkages and spatial associations than the other provinces. Similarly, Shanxi (41.7\%) had stronger industrial linkages and spatial associations than the other provinces in the Central region, Gansu (31.1\%) had stronger industrial linkages and spatial associations than the other provinces in the Western region and Liaoning (40.4\%) had stronger industrial linkages and spatial associations than the other provinces in the Northeastern region. In the provinces that have strong industrial linkages and spatial associations focus should be placed on related provincial high discharge sectors to reduce indirect industrial wastewater discharge. However, the industrial linkages and spatial associations resulting from fixed-asset occupancy in the industrial sectors are not as simple as those in single regions because they include inter-regional backward linkages and forward linkages. These linkages will be touched upon in the following subsections.

\subsection{Multi-Regional Backward Linkage and Forward Linkage of Fixed-Asset Occu- pancy in Industrial Sectors}

According to Equation (8), single-regional backward (and forward) linkages of fixed-asset occupancy in the industrial sectors of China, the Eastern region, the Central region, the Western region and the Northeastern region are 0.94 (and 0.97), 0.72 (and 0.68), 1.01 (and 1.11), 1.29 (and 1.41) and 0.98 (and 1.17), respectively. As for provincial regional backward (and forward) linkages of fixed-asset occupancy in the industrial sectors, only 9 provinces had single-regional backward and forward linkages that were both larger than 1. They are Shandong 1.81 (and 1.90), Inner Mongolia 1.09 (and 1.36), Shaanxi 1.16 (and 1.44), Anhui 1.95 (and 2.07), Chongqing 1.14 (and 1.17), Gansu 4.04 (and 4.51), Qinghai 1.78 (and 2.20), Xinjiang 1.21 (and 2.16) and Jilin 1.04 (and 1.24). Most of the 9 provincial regions are located in the Chinese Central region and the Western region.

The results of Equation (9) represent the inter-regional backward and forward linkages of fixed-asset occupancy in the Chinese industrial sectors in the Eastern region, Central region, Western region and Northeastern region and are shown in table 1. Regardless of inter-regional backward or forward linkages, the Eastern region shows strong linkages with the other three of China's four regions. For example, the Eastern region-Central region bilateral regional backward and forward linkages are 1.23 and 1.40, respectively, and the Central region-Eastern region interregional backward and forward linkages are 1.36 and 1.58, respectively. The case was the same 
for the bilateral regional linkages with the other two regions. The results were the same for the bilateral regional linkages in the Central region and Northeastern region. These results show that the Eastern region has close economic relationships with the Central region, Western region and Northeastern region. In fact, most provinces in the Eastern region are more developed than those in the other three regions. Additionally, most of the Central and Northeastern provincial regions have high industrial proportions, thus reinforcing their bilateral regional linkages.

Table 1 The backward and forward linkages of fixed-asset occupancy in the inter-regional industrial sectors

\begin{tabular}{lcccc}
\hline & The backward linkage & Status & The forward linkage & Status \\
\hline Eastern region-Central region & $1.23>1$ & strong & $1.40>1$ & strong \\
Eastern region-Western region & $1.11>1$ & strong & $1.44>1$ & strong \\
Eastern region-Northeast region & $1.15>1$ & strong & $1.66>1$ & strong \\
Central region-Eastern region & $1.36>1$ & strong & $1.58>1$ & strong \\
Central region-Western region & $1.15>1$ & strong & $0.96<1$ & weak \\
Central region-Northeast region & $1.20>1$ & strong & $1.79>1$ & strong \\
Western region-Eastern region & $1.35>1$ & strong & $1.69>1$ & strong \\
Western region-Central region & $1.22>1$ & strong & $1.50>1$ & strong \\
Western region-Northeast region & $1.06>1$ & strong & $1.67>1$ & strong \\
Northeast region-Eastern region & $1.14>1$ & strong & $1.71>1$ & strong \\
Northeast region-Central region & $1.19>1$ & strong & $1.76>1$ & strong \\
Northeast region-Western region & $0.95<1$ & weak & $1.79>1$ & strong \\
\hline
\end{tabular}

\subsection{The Dissimilarity of Coefficients and Linkages of Different Levels of Regional Classification}

This study focuses on multi-regional DIWDC, IO-TIWDC, and IOO-TIWDC in China and their single-regional backward and single-regional forward linkages of fixed-asset occupancy in a single region, 4 regions and 30 regions based on the aforementioned three types of IOO data. Different spatial aggregation effects are based on different levels of regional classification ${ }^{[42]}$, but DIWDC, IO-TIWDC, IOO-TIWDC, Single-Regional Backward Linkage (SRBL) and SingleRegional Forward Linkage (SRFL) are relative ratio values, and cannot be added directly. These three different classifications of the regional sectors are 6 fixed sectors, and the whole characters of these relative ratio values are expressed in Table 2 based on Equations (10) and (11). 
Table 2 The dissimilarity of coefficients and linkages of different levels of regional classification

\begin{tabular}{lcccc}
\hline & Different region & Total sector's number & Coefficient of variation & Gini coefficient \\
\hline \multirow{2}{*}{ DIWDC } & 1 region & 6 & 2.4495 & 0.8333 \\
& 4 regions & 24 & 2.5249 & 0.8709 \\
& 30 regions & 180 & 2.8687 & 0.8892 \\
\hline IO-TIWDC & 1 region & 6 & 0.7101 & 0.3398 \\
& 4 regions & 24 & 0.7723 & 0.3714 \\
& 30 regions & 180 & 0.9584 & 0.4217 \\
\hline IOO-TIWDC & 1 region & 6 & 0.5737 & 0.2825 \\
& 4 regions & 24 & 0.6510 & 0.3201 \\
& 30 regions & 180 & 0.8013 & 0.3716 \\
\hline SRBL & 1 region & 6 & 0.3445 & 0.1693 \\
& 4 regions & 24 & 0.3642 & 0.2007 \\
& 30 regions & 180 & 0.8659 & 0.3454 \\
\hline SRFL & 1 region & 6 & 0.4970 & 0.2411 \\
& 4 regions & 24 & 0.5053 & 0.2784 \\
& 30 regions & 180 & 0.9422 & 0.4195 \\
\hline
\end{tabular}

In Table 2, we can see that the dissimilarity of the three different levels of regional DIWDCs, IO-TIWDCs, IOO-TIWDCs and their SRBLs and SRFLs, whether coefficients of variation or Gini coefficients, became larger with the addition of more regions. Though this conclusion is based on an empirical analysis calculation, the result indicates that additional cross-sectional data would likely appear with additional regions. More of a region's own characteristics regarding industrial wastewater discharge and fixed-asset occupancy would be reflected through these cross-sectional data when a single region is divided into more specific regions, thus the dissimilarity of the relevant coefficients and linkages in the multi-regional IOO analysis would become larger. Therefore, when more regions are included in the multi-regional IOO analysis, additional different targeted policy suggestions would be provided which are based on the dissimilarity of the cross-sectional data.

\section{Conclusions}

Traditional IO analysis primarily examines economic flow. Professor Chen introduced occupancy of economic stock to IO analysis and proposed an IOO analysis in the 1980s, but IOO analysis focuses on a single region for a long time. This paper took Chinese industrial wastewater discharge as an example and completed IOO analysis in multiple regions. Then, the DIWDCs, IO-TIWDCs, IOO-TIWDCs, and backward and forward linkages of fixed-asset occupancy were calculated for industrial sectors in a single region, 4 regions and 30 regions of China using data from 2007. 
The main objectives of this study were: (i) To develop multi-regional IOO theories and methods based on single-region IOO theories and methods, and (ii) to show the pattern of industrial wastewater discharge coefficients of Chinese provincial industrial sectors and their implicit industrial linkages and spatial associations in 2007. In addition to considering industrial linkages and spatial associations for single regional discharge reductions, additional regions with more regional dissimilarities must be considered to develop suitable policies for regional sustainable development, which must reject a "one size fits all" approach. Environmental pollution is not only related to economic flow, including one-time raw material inputs, but is also related to economic stocks including gradual inputs that degrade over time, such as occupancy of fixed-assets. We have carried out a multi-regional IOO analysis of Chinese industrial wastewater discharge based on the theoretical integration of an environmental protection IO model, a multiregional IO model, and a non-competitive imports IO model, which help calculate industrial wastewater discharge accurately.

The results obtained (DIWDCs, IO-TIWDCs and IOO-TIWDCs) from multi-regional Chinese industrial sectors indicate that most of the Eastern regional provincial industrial sectors have lower DIWDCs, IO-TIWDCs, IOO-TIWDCs than the countrywide industrial sector did in 2007. The high DIWDCs, IO-TIWDCs and IOO-TIWDCs mainly arose in the Central and Western regional provincial industrial sectors. Furthermore, the Chinese provincial industrial sector that had the highest or lowest DIWDCs in all four regions showed similar trends in IO-TIWDCs and IOO-TIWDCs in the four regions. IOO-TIWDC was higher than IO-TIWDC due to introduced depreciation of fixed-asset occupancy.

We further investigated the backward and forward linkages of fixed-asset occupancy in industrial sectors in multiple regions. Strong single-regional backward linkages and forward linkages of fixed-asset occupancy in industrial sectors mainly occurred in the Central and Western regions. Strong inter-regional backward and forward linkages of fixed-asset occupancy in the industrial sectors were observed, as well as bilateral regional linkages between the Eastern region and the other three regions, similar to the observed Central-Northeastern regional bilateral linkages. Because this study is based on a Chinese multi-regional input-output table, more dissimilarity in these cross-sectional data (including coefficients and linkages) would emerge if the regions were divided more in the IO analysis. Therefore, if specific, targeted policy suggestions must be provided, specific divided regions should be used in the multi-region IO analysis.

We proposed an extended multi-regional IOO method and applied it to measure Chinese industrial wastewater discharge in 2007. This method has obvious advantages over traditional IO models, and could potentially deal with multi-regional occupancy problems. However, there was only the supporting data of fixed-asset occupancy in our empirical work, and additional data, such as land occupancy in different regions and sectors, was lacking. We believe that our research method can be used by analysts who wish to study regional industrial wastewater discharge more accurately. Our hope is that, with increasing use of multi-regional IOO analysis as conducted in this article, some occupancy problems, such as education occupancy, land occupancy, mineral occupancy, and so on, will be given further attention. 


\section{References}

[1] Angelakis A N, Bonoux L, and Lazarova V, Challenges and prospectives for water recycling and reuse in EU countries, Water Science and Technology: Water Supply, 2003, 3(4): 59-68.

[2] Asano T and Cotruvo J A, Groundwater recharge with reclaimed municipal wastewater: Health and regulatory considerations, Water Research, 2004, 38(8): 1941-1951.

[3] Chatila J G. Reclaimed waste water in some Middle Eastern countries: Pricing and perspective, Canadian Journal of Development Studies, 2004, 25(3): 481-497.

[4] Yang H and Abbaspour K C, Analysis of wasterwater reuse potential in Beijing, Desalination, 2007, 212(1-3): 238-250.

[5] Jiang Y, Wen J P, and Hu Z D, Development of new technology and method in industrial wastewater treatment process, Chemical Industry and Engineering Progress, 2004, 23(3): 256-259 (in Chinese).

[6] Liang Q, Gao R T, Xi B D, et al., Long-term effects of irrigation using water from the river receiving treated industrial wastewater on soil organic carbon fractions and enzyme activities, Agricultural Water Management, 2014, 135(c): 100-108.

[7] Aulinas M, Tolchinsky P, Turon C, et al., Argumentation-based framework for industrial wastewater discharges management, Engineering Applications of Artificial Intelligence, 2012, 25(2): 317-325.

[8] Zhang S Y, Han Y Z, Wang L, et al., Treatment of hypersaline industrial wastewater from salicylaldehyde production by heterogeneous catalytic wet peroxide oxidation on commercial activated carbon, Chemical Engineering Journal, 2014, 252: 141-149.

[9] Yu F, Cao D, Wang J N, et al., Prediction of industrial wastewater discharge and abatement expenditure, Research of Environmental Sciences, 2009, 22(8): 971-976 (in Chinese).

[10] Li L and Pan H L, Prediction of industrial wastewater discharge amount based on multivariate nonlinear regression, Journal of Jiangnan University (Natural Science Edition), 2011, 10(3): 309313 (in Chinese).

[11] Kong Y S and Liu X L, Prediction of wastewater emission in China, Environmental Science and Management, 2014, 39(3): 5-7 (in Chinese).

[12] Ministry of Environmental Protection of the People's Republic of China, The announcement of Ministry of Environmental Protection issued No. 30 in the year 2014, 2014, Available at: http://www. zhb.gov.cn/gkml/hbb/bgg/201405/t20140507_272557.htm (in Chinese).

[13] Tang Z P, Gong P P, Liu W D, et al., Sensitivity of Chinese industrial wastewater discharge reduction to direct input coefficients in an input-output context, Chinese Geographical Science, 2015, 25(1): 85-97.

[14] Leontief W, Environmental repercussions and the economic structure: An input-output approach, The Review of Economics and Statistics, 1970, 52(3): 262-271.

[15] Xie H B, Liu Z D, and Chen W, Quantitative analysis on the influential factors of industrial waste drainage, Resources and Environment in the Yangtze Basin, 2004, 13(4): 394-398 (in Chinese).

[16] Tang Z P, Liu W D, Liu Z G, et al., Regional difference and convergence of standardized discharge of industrial wastewater in China, Geographical Research, 2011, 30(6): 1101-1109 (in Chinese).

[17] Geng Y, Wang M, Sarkis J, et al., Spatial-temporal patterns and driving factors for industrial wastewater emission in China, Journal of Cleaner Production, 2014, 76: 116-124.

[18] Tang Z P, Fu X, and Zhou Z E, Identify important coefficients in China's sectors of discharge amount of industrial wastewater, China Population, Resources and Environment, 2008, 18(5): 123-127 (in Chinese). 
[19] Chen X K, Input-Occupancy-Output Analysis-Input-Output Table Extension. Chen X K (Ed.), input-output theory and practice in contemporary China, International Broadcasting of China Press, Beijing, 1988 (in Chinese).

[20] Chen X K, Input-occupancy-output analysis and its application in China, Chatterji M and Kuenne R E (Eds), Dynamics and Conflict in Regional Structural Change. London: Macmillan, 1990.

[21] Chen X K, Guo J E, and Yang C H, Extending the input-output model with assets, Economic Systems Research, 2005, 17(2): 211-225.

[22] Kneese A V, Ayres R U, and D'Arges R C, Economics and the environment: A materials balance Approach, The Johns Hopkins Press, Baltimore, 1970.

[23] Chen X K, Yang C H, et al., Input-Output Technique, Science Press, Beijing, 2011 (in Chinese).

[24] Leontief W, Gerbens-Leenes P W, Hoekstra A Y, and Meer V D T, The water footprint of energy from biomass: A quantitative assessment and consequences of an increasing share of bio-energy in energy supply, Ecological Economics, 2009, 68(4): 1052-1060.

[25] Tan R R, Foo D C Y, Aviso K B, et al., The use of graphical pinch analysis for visualizing water footprint constraints in biofuel production, Applied Energy, 2009, 86(5): 605-609.

[26] Yang H, Zhou Y, and Liu J, Land and water requirements of biofuel and implications for food supply and the environment in China, Energy Policy, 2009, 37(5): 1876-1885.

[27] Isard W, Interregional and regional input-output analysis: A model of a space economy, The Review of Economics and Statistics, 1951, 33(4): 318-328.

[28] Chenery H B, Regional Analysis. Chenery H B, Clark P G, and Pinna V C (Eds), The structure and growth of the Italian economy, US Mutual Security Agency, Rome, 1953.

[29] Victor P A, Pollution: Economy and Environment, University of Toronto Press, Toronto, 1972.

[30] Harris T R and Rea M L, Estimating the value of water among regional economic sectors using the 1972 national interindustry format?, Water Resources Bulletin, 1984, 20(2): 193-201.

[31] Duchin F, The conversion of biological materials and wastes to useful products, Structural Change and Economic Dynamics, 1990, 1(2): 243-261.

[32] Duarte R, Sanchez-Choliz J, and Bielsa J, Water use in the Spanish economy: An input-output approach, Ecological Economics, 2002, 43(1): 71-85.

[33] Velazquez E, An input-output model of water consumption: Analysing intersectoral water relationships in Andalusia, Ecological Economics, 2006, 56(2): 226-240.

[34] Lin C, Hybrid input-output analysis of wastewater treatment and environmental impacts: A case study for the Tokyo Metropolis, Ecological Economics, 2009, 68(7): 2096-2105.

[35] Ni J R, Zhong D S, Huang Y F, et al., Total waste-load control and allocation based on inputoutput analysis for Shenzhen, South China, Journal of Environmental Management, 2001, 61(1): $37-49$.

[36] Hubacek K and Sun L, Economic and societal changes in China and their effects on water use: A scenario analysis, Journal of Industrial Ecology, 2005, 9(1-2): 187-200.

[37] Okadera T, Watanabe M, and Xu K Q, Analysis of water demand and water pollutant discharge using a regional inputCoutput table: An application to the city of Chongqing, upstream of the Three Gorges Dam in China, Ecological Economics, 2006, 58(2): 221-237.

[38] Guan D and Hubacek K, A new and integrated hydro-economic accounting and analytical framework for water resources: A case study for North China, Journal of Environmental Management, 2008, 88(4): 1300-1313. 
[39] Chen X K, Liu Q Y, Qi S C, et al., Compilation and application of water input-occupancy-output table, China Statistics, 2003a, (8): 10-16 (in Chinese).

[40] Chen X K, Zhang H X, and Yang C H, Net backward effect calculation of water conservancy investment in capital construction in main river basins of China, Advances in Science and Technology of Water Resources, 2003b, 23(3): 6-9 (in Chinese).

[41] Su B, Huang H C, Ang B W, et al., Input-output analysis of $\mathrm{CO}_{2}$ emissions embodied in trade: The effects of sector aggregation, Energy Economics, 2010, 32(1), 166-175.

[42] Su B and Ang B W, Input-output analysis of $\mathrm{CO}_{2}$ emissions embodied in trade: The effects of spatial aggregation, Ecological Economics, 2010, 70(1): 10-18.

[43] Su B and Ang B W, Input-output analysis of $\mathrm{CO}_{2}$ emissions embodied in trade: Competitive versus non-competitive imports, Energy Policy, 2013, 56: 83-87.

[44] Dietzenbacher E, Pei J S, and Yang C H, Trade, production fragmentation, and China's carbon dioxide emissions, Journal of Environmental Economics and Management, 2012, 64(1): 88-101.

[45] Su B, Ang B W, and Low M, Input-output analysis of $\mathrm{CO}_{2}$ emissions embodied in trade and the driving forces: Processing and normal exports, Ecological Economics, 2013, 88: 119-125.

[46] Su B and Ang B W, Multi-region input-output analysis of $\mathrm{CO}_{2}$ emissions embodied in trade: The feedback effects, Ecological Economics, 2011, 71: 42-53.

[47] Zhang Z Y, Shi M J, Yang H, et al., An input-output analysis of trends in virtual water trade and the impact on water resources and use in China, Economic Systems Research, 2011, 23(4): 431-446.

[48] Liu W D, Chen J, Tang Z P, et al., China's 30 Provinces' Multi-regional Input-Output Table Theory and Practice in 2007, China Statistics Press, Beijing, 2012 (in Chinese).

[49] National Bureau of Statistics of China, Statistical Yearbook of China (2008), China Statistics Press, Beijing, 2008 (in Chinese).

[50] Deng Z G and Chen X K, Analysis of fuel ethanol from economics, energy value and food securitybased on China's fuel ethanol input-occupancy-output table in 2005, The 15th annual proceedings in Systems Engineering Society of China, 2008 (in Chinese).

[51] Tang Z P and Liu W D, An extended environmental protection input-occupancy-output model of the non-competitive imports type, Journal of Systems Science and Mathematical Sciences, 2013, 33(2): 159-170 (in Chinese).

[52] Sonis M, Hewings G J D, and Guo J M, A new image of classical key sector analysis: Minimum information decomposition of Leontief inverse, Economic Systems Research, 2000, 12(3): 401-423. 